\title{
Investigation of the Communication Skills Levels of Football Trainers According to University Football Team Sports' Perceptions
}

\author{
Hakan Sunay ${ }^{1}$,Recep Cengiz ${ }^{2}$, Onur Mutlu Yaşar $^{1}$ \\ ${ }^{1}$ (Sport Science Faculty, Ankara University, Turkey) \\ ${ }_{2}^{2}$ (Sport Science Faculty, Celal Bayar University, Turkey)
}

\begin{abstract}
This study's purpose is to prove the communication skills levels of football trainers according to perceptions of football players. The universe of the research is formed by 178 football players who participated in the football tournament amongst the second league universities in Sanlurfa between $30^{\text {th }}$ April and $5^{\text {th }}$ May in 2013. The sample of the research is composed of 117 football players who took part in the research voluntarily. The data of the study were collected with 'Trainer Communication Skills Scale' 'in the type of 5-Likert, consisting of 48 items and one size which was developed by Yllmaz and his colleagues. Arithmetic mean and Anova tests were used in statistical analysis of the study. According to the results obtained in this descriptive study, the level of communication skills of the trainers was adequate but at the level required to be developed $(X=3,96 \pm .523)$. In addition, according to the results of the research, the communication skills levels of the coaches of ages between 18-21 years were found to be higher than the ages of 22-25 and 26-and above age groups.
\end{abstract}

Keywords: Coaches, Football, Communication

\section{Introduction}

The concept of communication has become an important factor in humans' expressing themselves as a social being with the history of humanity [1].There are many studies in literature about the concept of communication $[2,3,4,5,6,7,8,9,10,11,12]$. Communication is expressed as "communication" in English which is derived from the word "communis" in Latin [13].

The concept of communication has drawn the attention of many sciences such as sociology, psychology and management sciences and every scholar has expressed this concept in his own terms [14]. In this context, more than one definition has emerged about the concept of communication. According to Keyton, [15]communication is the feeling and thought exchanges between living things. In another definition, communication is expressed as the total of intellectual and relational activity which is compulsory for the continuity of human existence[16].In another definition, communication is defined as the process of producing information and giving meaning [17]. According to definitions made; it is possible to define communication as emotions and thought making processes and exchanges of living things.

Effective use of communication has a significant importance both in social relations and in professional life relationships [18]. Communication weaknesses such as misunderstandings, gossip, prejudices in the organization harm to the individual and the organization by preventing the creation of expected synergies [19]. The concept of communication skills emerges at the point of the necessity of utilizing the power of communication activities. Communication skills can be defined as the intelligent use of tools that are assessed in the removal of the obstacles for effective communication[20]. Communicating action generally takes place in two forms as verbal and non-verbal communication. While verbal communication includes speaking and writing by using words, non-verbal communication refers to communication got into touch by expressions and body movements [21].

Within these two types, there are certain principles to use communication effectively. These are [22];

- Show responses and ideas clearly

- Respect people's thoughts and behaviours

- Encourage people to talk

- Communicating free from prejudices

- Listen people carefully

- Clear and good use of words and phrases

- Use the feedback mechanism in the communication process

In addition to the principles used to provide effective communication in literature, attention has also been drawn to situations that prevent communication. These situations can be listed as follows [23];

- Not listening 
- Complicated messages

- $\quad$ Prejudices

- Exaggerated statements

- Interrupting expression

The concept of communication whose effect is accepted in many working areas has a significant impact on the functioning and management of sports organizations. During the process of change of the sport concept, it is not only a physical activity anymore, but sport has become a major social event and also an important industry [24]. At the point of this big sector's management, the importance of interpersonal communication and organizational communication is increasing. It is accepted that psychological performance is influential in sports field and it is stated that communication concept is important in providing psychological development [25]. When the concept of communication is evaluated in this context, the importance of sports environments in which interpersonal communication is intensively experienced is also increasing. Particularly, in the role of coach in sports teams, it can be considered that the activities of communication are influential in coaching process which has the power to directly influence the performances of athletes and teams.

Bloom has stated that coaches with effective communication skills have a positive effect on all the factors in coaching process and also that the performances of the athletes working with such coaches increase[26].Moreover, Burton and Readeke [27] stated that coaches' communication skills are very important at the point of being successful and coaches who are not adequately communicative can experience problems in achieving success and sustaining it even if they have high qualifications.

Donoughe and Mayes [28] who stated that sports performance has a lot of parameters and that improving performance is a difficult process, also pointed out that coaches' communication skills are an important factor in raising the performance of athletes.

That the coaches can make their profession more effective and be more successful in their work in the case of good use of communication process can be stated by moving from these opinions and thoughts (29). In this context, the purpose of the study is to examine coaches' communication skills and detect athletes.

\section{Universe and Sample}

\section{Method}

The universe of the research was composed by 178 football players who participated in the football tournament amongst the second league universities in Şanliurfa between $30^{\text {th }}$ April and $5^{\text {th }}$ May in 2013.117 volunteer football players formed the sample of the research. In the selection of the sample of the research, convenience sample type which is one of the non-random sample types was used.

\section{Data Collection Tool}

The data of the study were collected with "Trainer Communication Skills Scale", in the type of 48 items and one size which was developed by Y1lmaz and his colleagues[30]. "Arithmetic mean of the scores is between 5.00-4.20 communication skill is effective at the highest level, 4.19-3.40 is effective but should improve, between 3.39-2.60 is average (middle level), between 1.80-2.55 is weak and 1.00-1.79 is ineffective"" which is frequently used in this type of scoring method was adopted and interpretations were made in this direction.

\section{Data Collection}

Necessary permission is taken from the football players by stating that they can withdraw without request, participation in the research is based on totally voluntary basis and explaining the purpose of the research to the football players in the scope of the study. A total of 178 scales were distributed to the football players during the collection of data, but 61 scales were not included in the survey due to incomplete or incorrect information and statements.

\section{Analysis of Data}

SPSS 21 package program was used to analyse the obtained data. Skewness and Kourtois values were determined and the results were found to be in the range of $+2,-2$ find out whether the data had a normal distribution or not [31]. The structure validity of the scale was examined by the factor analysis and it was found that total correlations of 48 items changed between 56 and 89. The internal consistency (Cronbach's alpha coefficient) of the scale was found to be 80.At this point, it was understood that the reliability level of the scale is high. Arithmetic mean and Anova tests were also used in the analysis of data. 
Table1. Personal Information of Footballers

\begin{tabular}{|c|c|c|c|}
\hline Personal Information & Sub Groups & $\begin{array}{c}\text { Frequency } \\
\text { (f) }\end{array}$ & Percentage(\%) \\
\hline \multirow{3}{*}{ Age } & 18-21 Age range & 60 & 51,3 \\
\cline { 2 - 4 } & 22-25 Age range & 31 & 26,5 \\
\cline { 2 - 4 } Athletic History & 26- and above age range & 26 & 22,2 \\
\cline { 2 - 4 } & 1-3 years & 25 & 21,4 \\
\cline { 2 - 4 } & 4-7 years & 53 & 45,3 \\
\hline \multirow{3}{*}{ Department } & Besyo and equal departments & 39 & 33,3 \\
\cline { 2 - 4 } & Other Faculties & 26 & 53,8 \\
\cline { 2 - 4 } & Vocational Colleges & 28 & 22,2 \\
\hline & Total & $\mathbf{1 1 7}$ & $\mathbf{1 0 0}$ \\
\hline
\end{tabular}

*Besyo: School of Physical Education and Sports

When the data in Table 1 were examined, it was seen that $60(\% 51,3)$ of the footballers participating in the study were in the 18-21 age range, $31(\% 26,5)$ were in the 22-25 age range, $26(\% 22.2)$ of them were 26 and above. In addition, when the athletic backgrounds of the participating footballers were evaluated, that 25 (\%21, 4) had between 1-3 years, $53(\% 45,3)$ had between $4-7$ years and $39(\% 33,3)$ of them had 8 years and above experience of athleticism were seen. When examined that in which departments in universities the footballers who participated in the research were educated, that most of them $(n=63, \% 53,8)$ were educated at the School of Physical Education and Sports ( Besyo) or in the balanced departments, $26(\% 22,2)$ were in the other faculties of the universities and 28 of the students $(\% 23,9)$ were educated at vocational colleges in universities were detected.

\section{Findings}

Findings of this study for determining communication skills level of coaches participating in the intercollege football tournament held in Şanlıurfa in 2013are given below.

Table2. Average Score and Standard Deviation of Coaches According to Athlete Perceptions

\begin{tabular}{|c|c|c|c|}
\hline \multirow{2}{*}{ Sports Branch } & \multicolumn{3}{|c|}{ Communication Skill } \\
\cline { 2 - 4 } Football & $\mathbf{N}$ & $\overline{\mathbf{X}}$ & S.S \\
\hline & 117 & 3,96 & .523 \\
\hline
\end{tabular}

When Table. 2 is examined, it was seen that the level of communication skills of coaches according to athlete perceptions is $\bar{X}=3,96 \pm .523$. As a result, it was determined that the level of communication skills of football coaches is effective but at a level that should be improved.

Table 3. Variant Analysis Results of Differences between Groups’ Average Scores by Variables

\begin{tabular}{|c|c|c|c|c|c|c|}
\hline Variable & Groups & $\mathbf{N}$ & $\overline{\mathrm{X}}$ & S.S. & $\mathbf{F}$ & Sig. \\
\hline \multirow{3}{*}{ Age } & $18-21$ & 60 & 4,22 & .624 & \multirow[t]{3}{*}{1.911} & \multirow[t]{3}{*}{,043* } \\
\hline & $21-15$ & 31 & 3,86 & .565 & & \\
\hline & 26- and above & 26 & 3,84 & .546 & & \\
\hline \multirow{3}{*}{ Athletic History } & $1-3$ & 25 & 3,75 & .527 & \multirow[t]{3}{*}{1.338} & \multirow[t]{3}{*}{, 775} \\
\hline & $4-7$ & 53 & 3,82 & .687 & & \\
\hline & 7- and above & 39 & 3,73 & .543 & & \\
\hline \multirow{3}{*}{ Department } & Besyo & 63 & 4,16 & .539 & \multirow[t]{3}{*}{1.256.} & \multirow[t]{3}{*}{,047* } \\
\hline & Other Faculties & 26 & 3,94 & .648 & & \\
\hline & Vocational Colleges & 28 & 3,88 & .596 & & \\
\hline
\end{tabular}

When the coach communication skills were examined according to the age variable of athletes, the level of communication skills of the coaches according to the perceptions of the athletes between the ages of 1821 are statistically higher than those of the athletes at the age of 22-25 and 26-above.

When the data in Table. 3 were evaluated, the coach communication skills according to the athlete perceptions are not statistically different from when the athletes were examined according to their athletic backgrounds, although the highest value was found among the athletes with an athletic past of 4-7 years between groups.

When the trainers' communication skills according to the perceptions of the athletes were evaluated by the departments where the athletes were trained, the communication skills of the trainers of Besyo students and 
students in the equal educational institutions were found to be higher than the athletes who were educated in other faculties and vocational colleges.

\section{Discussion and Conclusion}

Within the scope of the research, the communication skills levels of the coaches according to the perceptions of footballers were examined and the communication skills levels of the coaches were determined to be sufficient but at a level that should be improved $(\bar{X}=3,96 \pm .52)$. It can be shown that the level of communication skills of the coaches is adequate but needs to be improved in the scope of the research that the coaches actually have good communication with the players, but that this is caused by the difference between the ages of the coaches participating in the study and the college coaches. It can be said that the rapidly developing and changing social environment may negatively affect the communication within the age groups. Y1lmaz and his colleagues (2009) conducted researches aimed at determining the levels of communication skills of coaches in different sports branches according to the athlete perceptions; team sports coaches have been identified at the highest level of effective communication skills. The reason for the difference between the results of the study done by Yilmaz and his friends (2009) and the results of the study that is done is that Yilmaz and his colleagues are involved in the team sports coaches as well as the athletes who perform individual sports are included in the study and the athlete interaction is higher in the individual sports coaches. . In addition in the study that Akabay and Kuru has done (2013) called the communication level and motivation relationship of female soccer players with their coach according to the perceptions of female footballers, the level of communication of their coaches was determined at an adequate level. In addition, according to the perceptions of female athletes performed by Haselwood and her colleagues [32], the results of the study to determine the communication skill levels of the coaches were determined to be sufficient but not perfect. In this context, the results of the work done by Abakay and Kuru (2013) and Haselwood (2005) and his colleagues are similar.

According to the perceptions of the footballers, when the coach communication skills were examined according to the age of the footballers, the communication skills of the coaches were statistically higher than the athletes in the age range of 22-25 years and 26 years. According to the perceptions of younger aged footballers, it can be shown that the reason for the higher level of communication skills of the coaches is that younger footballers have a positive view of their new university education and that they may be more willing to coach or trainers. In the researches for determining the levels of coach and athlete education which Selazig and Cepikkurt (2014) has made, it has been determined that there is no significant difference between age and communication skill level. The reason for this is that the sample of the research done by Selaziğ and Cepikkurt [33] is due to the fact that the sportsmen in different sports branches and the athletes in the sample are close to each other. In this context, there is no similarity between the results of the research done by Selazig and Cepikkurt (2014) and the results of the research done.

According to the athlete's perceptions, when the trainer's communication skills are examined according to the athlete's history variables, the highest value is not statistically significant between the groups despite the fact that the athletes with the athletic past between the years 4-7 years appear. This may be due to the fact that the footballers who have been in the sporting history for 1-3 years cannot adapt to the sports environment exactly yet and that the footballers who have 8 years and more years of athletic history are working with many coaches according to the assumption that their coaches are more selective about the adequacy of communication skills. In the study conducted by Kissal and colleagues [34] in the context of comparison of communication skills of nursing and physical education sports high school students, no statistical difference was found regarding the students' sporting and non-sporting variables. In this context, the results of the work done by Kissal and his friends (2016) are similar to those of the work done.

According to the perceptions of the athletes, the communication skills of the trainers were higher in the perceptions of the footballers who were trained in other faculties and vocational colleges according to the perceptions of the sportsmen in Physical Education and Sport Department and the equal educational institutions. This may be due to the assumption that the coaches of college soccer teams are usually made up of lecturers who are currently working at the Physical Education and Sport Department and balanced educational institutions and that their communications are higher because of the interaction of the lecturers and students who are spending time in the same educational institution.

\section{In conclusion;}

1. The level of communication skills of football coaches working at university teams according to the perceptions of the footballers is sufficient but it has been determined at the level of development.

2. It has been determined that the perceived communication skill levels for coaches decrease as footballers age in university teams progress.

3. There was no significant relationship between the athletic background variables of footballers working in university teams and the perceived communication skill levels of the coaches. 
4. When the variables of the institutions in which the trainers of university teams are trained are examined, the perceived communication skill levels of the coaches are higher in the students who are educated in the Physical Education and Sport Department and the equal departments.

\section{References}

[1]. Mutlu, E. (1994). Communication Dictionary, Ankara: Ark Publishing House.

[2]. Culver, D. M. (1999). Coach-athlete communication within a national Alpine ski team. University of Ottawa (Canada).

[3]. Tutar, H.,\&Y1lmaz, M. K. (2005). General Communication: Concepts and Models. Seckin Publishing.

[4]. Tepeköylü, Ö.,Soytürk, M., \&Çamlıyer, H. (2009). Analysis of Perceptions of Communication Ability of the Students of Physical Education and Sports (Physical Education and Sports Department) in Terms of Some Variables, SPORMETRE Journal of Physical Education and Sports Science. VII (3) 115-124

[5]. Ulukan, H. (2012). The influence of communication skills on team and individual sportsmen. KaramanogluMehmetbey University, Institute of Social Science, Post Graduate Thesis.

[6]. Uzuntas, A. (2013). Effective Communication: to understand and to explain, Kastomonu Journal of Education. 21(1), 11-20.

[7]. Grunig, J. E. (2013). Excellence in public relations and communication management. Routledge.

[8]. Brummett, B. \&Ishak, A. (2013). Sports and identity: New agendas in communication. Routledge.

[9]. Miller, L. (2015). Sports Communication as a Way to Develop Critical Competencies in the L2 Classroom. RELC Journal, 46(1), 89-104.

[10]. Oboeuf, A. Fernandes, E., Lecroisey, L., D’Arripe, A., Duployé, A., \&Collard, L. (2016). Study of Responses from 250 Players and 50 Coaches on Communication in Team Sports. Staps, (1), 65-80.

[11]. McNeese, N. J. Cooke, N. J., Gray, R., \&Fedele, M. (2017). Knowledge Elicitation Methods for Developing Insights into Team Cognition during Team Sports. In Advances in Human Factors in Sports and Outdoor Recreation (pp. 3-15). Springer International Publishing.

[12]. Lurie, C. (2016). The role of self-education in training of specialist in physical culture and sports development.

[13]. Lunenburg, F. C. (2010). Communication: The process, barriers, and improving effectiveness. Schooling, 1(1), 1-11.

[14]. Yetim A., Cengiz, R. (2012) Communication and Sports. Berikan Publishing, Ankara

[15]. Keyton,J.(2011).Communication and organizational culture: keyton understanding work experience. Thousand Oaks, CA: Sage.

[16]. Erdoğan, I. (2011). To Understand Communication. ISBN 978-975-94546-3-0 Ankara

[17]. Dökmen, Ü. (2004). Communication Conflicts and Empathy (27. bs.). Istanbul: Sistem Publishing

[18]. Korkut, F. (2005). Adult Communication Skills Education. Hacettepe University Journal of Education Faculty, 28(28).

[19]. Temel A. (2004). The importance of interpersonal communication in effective team work. Istanbul University Journal of Communication Faculty, 19(1): 411-433

[20]. M.T.D. Training (2010). Effective communication skills. Bookboon.

[21]. Zuckerman, M., De Paulo, B. M., \&Rosenthal, R. (1981). Verbal and non-verbal communication of deception. Advances in experimental social psychology, 14, 1-59.

[22]. Juliana,B.(2016)AmoudUniversityCommunicationskillsForUndergraduatesLectureNotes http://amouduniversity.org/images/Class_Notes/Communication_Skills_Class_Notes_April_2016.pdf

[23]. Erven, B. L. (2002). Overcoming barriers to communication. Ohio State University. Hyperlink [http://www.-agecon. ag. ohiostate. edu/people/erven. 1/HRM/communication. pdf], 7

[24]. Katırc1, H.,\&Uztug, F. (2009).Communication Management in Sports Clubs: A Study on Communication Practices of Sports Clubs in Professional Football Leagues in Tukey. Anadolu University Journal of Social Sciences, 9(1)

[25]. Abakay, U.,\& Kuru, E. (2013). The communication level and achievement motivation relation to coaching to for woman footballers. Gaziantep University Social Science Journal 12(1).

[26]. Bloom G.A. Characteristics, Strategies and Knowledge of Expert Team Sport Coaches. PhD.Diss, University of Ottawa, Ontario, Canada, 1997.

[27]. Burton, D. \&Readeke, T. (2008). Sport psychology for coaches. International Journal of Sports Science and Coaching, 3(2), 291292.

[28]. Donoghue, P.,\&Mayes, A. (2013). Performance analysis, feedback and communication in coaching.

[29]. Yılmaz, İ., Çimen, Z., \&Bektaş, F. (2009) Comparison of Communication Skill Levels of Individual and Team Sports Trainers: Perceptions of Athletes. Journal of Physical Education and Sport Sciences 11(4).

[30]. Yilmaz, İ., Çimen, Z. (2008) Leadership Behavior Analysis and Communication Skill Levels of Coaches in Different Sport Branches on the Perceptions. Gazi University Institute of Health Science, Doctorate Thesis.

[31]. George, D.\& Mallery, M. (2010). SPSS for Windows Step by Step: A Simple Guide and Reference, 17.0update (10a ed.) Boston: Pearson.

[32]. Haselwood, D. M. Joyner, A. B., Burke, K. L., \&Geyerman, C. B. (2005). Female athletes' perceptions of head coaches' communication competence. Journal of Sport Behavior, 28(3), 216

[33]. Selazı ̆̆, S.,\&Cepikkurt, F. (2015). Celal Bayar Univesity Journal of Physical Education and Sports Science, 9(1), 11-18.

[34]. Kissal, A., Kaya, M., \&Koç, M. (2016). An Evaluation of Communication Skills Levels and Affecting Factors of Nursing and Physical Education and Sports Students. 